\title{
Gerenciamento da cadeia de suprimentos no setor automobilístico: um estudo de caso no consórcio modular
}

\author{
Ana Carolina Cardoso Firmo (UNIFEI) accfirmo@unifei.edu.br \\ Renato da Silva Lima (UNIFEI) rslima@unifei.edu.br
}

\begin{abstract}
Resumo
O ambiente industrial envolvido em alta competitividade de mercado vem apresentando novas técnicas de gestão, entre as quais se insere o Gerenciamento da Cadeia de Suprimentos (Supply Chain Management - SCM). O objetivo desse trabalho é analisar as práticas de SCM no setor automobilístico, em especial, o arranjo produtivo do consórcio modular. Após a realização de um levantamento bibliográfico sobre SCM e práticas de SCM no ramo automobilístico, foi conduzido um estudo de caso na planta da Volkswagen Caminhões e Ônibus, localizada na cidade de Resende - RJ, no qual foram entrevistados alguns dos gerentes industriais dos módulos que compoem o consórcio modular, além de observações diretas efetuadas pelo pesquisador. De modo geral, pode-se constatar que o arranjo produtivo tipo Consórcio Modular é mais adequado às atividades relacionadas à montagem do que as de fabricação. Destaca-se também a maior integração da montadora com seus fornecedores, conseqüência da proximidade física entre os mesmos e do maior envolvimento dos fornecedores, desde o projeto até a montagem final do veículo.

Palavras Chaves: Consórcio Modular; Gerenciamento da cadeia de suprimentos; Indústria automobilística.
\end{abstract}

\section{Introdução}

O ambiente industrial tem apresentado diversas mudanças técnicas e organizacionais, incluindo algumas fusões e aquisições que buscam acrescentar estratégias para a competitividade, integrando as atividades que agregam valor e são percebidas pelo cliente (CARLINI, 2002). Neste enfoque, a década de 1980 foi marcada pelo uso de novas tecnologias e estratégias de fabricação que buscavam a redução de custos e maior competitividade, como o just in time, o kanban, a produção enxuta e o gerenciamento da qualidade total, cuja utilização foi responsável por melhorias nos processos produtivos. Mais recentemente, o Gerenciamento da Cadeia de Suprimentos - SCM (do inglês, Supply Chain Management) vem sendo utilizado como uma das ferramentas mais importantes na busca por maiores lucros e participação no mercado (SIMCHI-LEVI et al., 2003). Segundo Lummus \& Vokurka (1999), o interesse em SCM se intensifica a partir da década de 1990 devido a fatores como: a verticalização e maior especialização das organizações; aumento na competitividade nacional e internacional; o potencial diferencial competitivo obtido por meio do SCM, proporcionando, entre outros, a redução nos custos e a maior agilidade de entrega.

Além disso, com o passar dos anos, o modelo tradicional de relacionamento entre indústrias e seus fornecedores, baseado na competição, vem perdendo espaço para modelos baseados na cooperação e nas alianças de longo prazo, que integram alguns dos conceitos de SCM. Estes novos modelos implicam em uma nova distribuição de responsabilidades, quase sempre acompanhada de uma maior terceirização da produção de bens e da prestação de serviços (NÓBREGA JR, 2000). A competição de mercado passa a ocorrer não mais entre empresas, mas entre as cadeias de suprimentos, requerendo assim um elevado grau de integração e coordenação entre os membros da cadeia de suprimentos (JESUS, 2003). 
Segundo Pires (2004), o desenvolvimento e a aplicação dos conceitos de SCM apresenta grande crescimento nas indústrias automobilísticas devido ao alto nível de competitividade existente nesta atividade e ao seu pioneirismo na implantação de inovações tecnológicas e gerenciais dentro do ramo industrial.

A aplicação de alguns conceitos de SCM aliados aos novos modelos de relacionamento entre a indústria e seus fornecedores permitem a elaboração e implantação de novos arranjos produtivos, como por exemplo, os Condomínios Industriais e o Consórcio Modular, esse último de particular interesse para este trabalho, que baseia-se na transferência das atividades de montagem dos produtos para os fornecedores de módulos, ou seja, subconjuntos do produto final. Para sua consolidação, esses fornecedores passam a ocupar a mesma planta da empresa responsável pelo consórcio.

O objetivo desse trabalho é analisar as principais práticas de SCM em uma montadora de veículos comerciais que adota a estrutura de consórcio modular e se responsabiliza pela coordenação da cadeia de suprimentos na qual está inserida. Para tanto, foi realizado um estudo de caso na planta da Volkswagen Caminhões e Ônibus, localizada na cidade de Resende - RJ, no qual foram entrevistados alguns dos gerentes industriais dos módulos que compoem o consórcio modular, além de observações diretas efetuadas pelo pesquisador. $\mathrm{O}$ trabalho está estruturado da seguinte maneira: após esta breve introdução são apresentadas, nas seções 2 e 3, algumas considerações teóricas relativas ao gerenciamento da cadeia de suprimentos $(\mathrm{SCM})$ (seção 2) e às práticas de SCM no ramo automobilístico (seção 3). $\mathrm{Na}$ seqüência, na seção 4, apresenta-se a condução do estudo de caso. Finalmente, são apresentadas as considerações finais do trabalho, na seção 5, seguidas da lista com as referências bibliográficas.

\section{Gerenciamento da cadeia de suprimentos (SCM)}

A cadeia de suprimentos é definida como o conjunto de atividades que envolvem a distribuição do produto para o consumidor final, desde a aquisição de matéria prima, manufatura e montagem, armazenagem, controle de estoques, controle de entrada e saída de materiais, distribuição entre os elos da cadeia, entrega ao consumidor e também o sistema de informações envolvido (LUMMUS \& VOKURKA, 1999). Furlaneto (2002) ressalta que a cadeia de suprimentos é um sistema envolvendo os fornecedores de matéria prima, os processadores, os serviços de distribuição e comercialização e os clientes, todos estes ligados por meio da aquisição de produtos e fluxo de recursos e informações. Sua formação deve ser uma decisão estratégica, por ser composta por diversas empresas.

Segundo Lummus \& Vokurka (1999), o gerenciamento da cadeia de suprimentos (SCM) é responsável por integrar e coordenar as atividades da cadeia de suprimentos, conciliando as principais áreas da cadeia, com o intuito de promover a produção e distribuição de mercadorias na quantidade, local e momento certos (SIMCHI-LEVI et al., 2003). Bowersox (2001) define SCM como uma visão expandida da administração de materiais tradicional, abrangendo também os fornecedores e clientes. O principal objetivo deste novo modelo de gerenciamento é o aumento da sinergia entre os elos da cadeia, devido a grande relevância do compartilhamento de informações, buscando assim obter maior nível de satisfação do cliente, redução de custos e acréscimo no valor agregado. A customização de bens e serviços, o uso de soluções integradas e o desenvolvimento de competências diferenciadas são em geral os principais responsáveis pelo acréscimo de valor agregado a um dado produto ou serviço (PARRA, 2000).

Para Fleury (1999) o SCM é uma abordagem sistêmica de razoável complexidade, que implica em alta interação entre os participantes da cadeia, exigindo a consideração simultânea das diversas estratégias de mercado tanto individuais quanto inter-organizacionais. Lummus 
\& Vokurka (1999) apresentam alguns pontos que devem ser considerados na gestão da cadeia de suprimentos:

- Associação das estratégias da cadeia de suprimentos com as da empresa como um todo, para alcançar os objetivos da corporação;

- Identificação das metas estabelecidas na cadeia e o desenvolvimento de medidas de desempenho para atendê-las;

- Desenvolvimento de sistemas para a obtenção de previsões de demanda mais alinhadas às variações de mercado;

- Melhor gestão do relacionamento com fornecedores, buscando redução de custos e cumprimento dos prazos de entrega acertados;

- Desenvolvimento de processos logísticos customizados para atender cada segmento de consumidores;

- Desenvolvimento de uma rede de informações capaz de oferecer visão clara de todo o fluxo de produtos e permitir apoio à decisão;

- Adoção de medidas de desempenho interfuncionais e interempresariais para que haja associação entre todos os aspectos da cadeia de suprimentos.

Alguns conceitos e práticas de SCM que vêm sendo bastante utilizados no setor automobilístico são apresentados na próxima seção. Alguns deles não são exclusivos deste ramo de atividade, mas são aqui destacados devido à importância das montadoras de automóveis na utilização e desenvolvimento dos mesmos.

\section{Práticas de SCM no ramo automobilístico}

\subsection{Re-estruturação das cadeias de suprimentos}

Esta prática foca a consolidação da base de fornecedores e clientes, com o intuito de definir as empresas com as quais se deseja construir uma parceria mais efetiva. É levada a cabo por meio da identificação e alinhamento de competências, para se diferenciar perante a concorrência e atrair os consumidores finais (PIRES, 2004). No ramo automobilístico, esta prática vem sendo caracterizada por uma redução do número dos fornecedores diretos, transferência de atividades para os mesmos e conseqüente definição de novos atributos a serem atendidos. Estes fatores incentivam o desenvolvimento de novas formas de gestão, como o Condomínio Industrial e o Consórcio Modular, na busca de uma maior integração entre as montadoras e seus fornecedores.

\subsection{Desenvolvimento de fornecedores}

Segundo Pires (2004), o desenvolvimento de fornecedores pode variar de uma avaliação informal das operações de produção até a criação de um programa de investimentos conjunto em treinamento, melhorias de produto e processos, dentre outros. Em geral, busca-se o comprometimento de capital e de recursos humanos e o compartilhamento adequado de informações, além de indicadores de desempenho para o processo de desenvolvimento. Como conseqüência da redefinição das empresas que compõem a cadeia de suprimentos, as montadoras vêm mostrando maior envolvimento no desenvolvimento e certificação de seus fornecedores, sejam eles diretos ou não. A busca por melhoria de qualidade é cada vez mais constante e nota-se que investimentos em desenvolvimento via de regra levam à redução de custos aos integrantes da cadeia.

\subsection{Outsourcing}

Segundo Cabral (2004), outsourcing significa suprir parte dos produtos e serviços necessários por meio de fontes externas, evidenciando a decisão da organização de utilizar os recursos 
disponíveis no mercado, desde que existam parceiros confiáveis e tecnologicamente capazes de atender aos critérios de fornecimento estabelecidos. Este conceito visa, por meio da concentração nas principais atividades do negócio: maximizar os retornos de investimento; reduzir os riscos tecnológicos e financeiros; superar a falta de recursos internos; liberar recursos produtivos; aumentar eficiência e eficácia dos processos; promover o acesso mais rápido a tecnologia e expandir os benefícios da Reengenharia.

A indústria automobilística apresenta alto grau de subdivisão de seus produtos em diversos componentes e sistemas, que são produzidos por seus fornecedores, caracterizando a prática de outsourcing e permitindo à montadora maior envolvimento com seu core business.

\subsection{In plant representatives}

$\mathrm{O}$ in plant representatives caracteriza-se pela presença de representantes de determinadas empresas trabalhando em tempo integral em seus fornecedores e/ ou clientes, criando uma comunicação dinâmica e mais confiável entre as empresas envolvidas (PIRES, 2004). Esta prática apresenta destaque entre as montadoras, já que parte de seus principais fornecedores disponibilizam um representante em tempo integral dentro da empresa automobilística onde, por meio de um relacionamento mais próximo entre as empresas, correções de falhas de fabricação ou projeto podem ser corrigidas de forma mais eficaz. Algumas montadoras disponibilizam ainda alguns de seus funcionários nas plantas de seus fornecedores, buscando garantir maior agilidade na solução de possíveis problemas principalmente relacionados ao suprimento.

\subsection{Early supplier involvement (ESI)}

O envolvimento dos fornecedores desde a fase inicial do projeto do produto é uma prática de SCM que apresenta grande expansão. Neste caso, o fornecedor traz sua competência e conhecimentos para criação de um produto de forma mais rápida, ao menor custo e maior qualidade (PIRES, 2004). O ESI não é um processo estático, no qual a empresa o adota ou não, mas um envolvimento contínuo de fornecedores no processo de desenvolvimento (PARRA, 2000). Isto se evidencia no ramo automobilístico, onde geralmente o envolvimento dos fornecedores ocorre desde o início do projeto de um veículo até a fase de definições de abastecimento, permitindo ao fornecedor o desenvolvimento de toda a sua capacidade produtiva e o ferramental necessário. Este relacionamento mais próximo entre empresas é favorecido devido a práticas como: contratos mais duradouros; número reduzido de fornecedores; desenvolvimento dos fornecedores, entre outros, todos eles embasados no gerenciamento da cadeia de suprimentos.

\subsection{Consórcio Modular}

Segundo Marx et al. (1997), o conceito de Consórcio Modular, criado no ramo automobilístico, baseia-se na transferência de todas as operações de montagem para os fornecedores de primeiro nível, agora referenciados como modulistas. Este novo sistema visa, entre outras coisas, produção mais ágil e redução de custos quando comparados ao modelo tradicional de montagem. Os veículos são produzidos em uma linha de montagem convencional e os parceiros são responsáveis por completar as operações de montagem. $\mathrm{O}$ capital de investimento e a gestão dos processos de produção diários (organização do trabalho, logística, manutenção) são providenciados pelos módulos.

Pires (2004) ressalta que a viabilidade do consórcio modular na cadeia de suprimentos automotiva é limitada ao projeto, manufatura e linha de produção. Isto é caracterizado por um longo contrato de relacionamento entre a montadora e um pequeno número de fornecedores de primeira ordem, no qual: 
- Os fornecedores assumem a responsabilidade pela montagem final dos módulos na linha de produção dos veículos, investimentos em operações e gerenciamento da cadeia de suprimentos do módulo;

- A montadora providencia a planta e a linha de montagem, assumindo as responsabilidades de projeto, coordenação da planta, testes finais, comercialização dos veículos e assistência técnica.

Um dos aspectos de maior relevância dentro desse novo modelo industrial é a necessidade da troca de informações entre todas as suas partes constituintes. Todas as decisões de produção são tomadas em conjunto, buscando a melhor opção para os diferentes parceiros.

De posse da base conceitual, para se atingir o objetivo de confrontar as práticas de SCM com os conceitos do consórcio modular, foi conduzido um estudo de caso em uma montadora de veículos comerciais, detalhado na próxima seção.

\section{Estudo de Caso}

Do ponto de vista de sua natureza, a abordagem qualitativa é a mais adequada para este estudo, pois o pesquisador objetiva interpretar como as práticas do consórcio modular influenciam a integração e coordenação na cadeia de suprimentos estudada, além de analisar a utilização das práticas de SCM neste contexto. Yin (2001) ressalta que o método de pesquisa de estudo de caso deve ser aplicado na análise de eventos contemporâneos, onde se busca responder questões do tipo: Como? e Por quê? Ressalta ainda que este método pode utilizar seis fontes de dados na busca por evidências. São elas: documentação, dados arquivados, entrevistas, observação direta, observação participante e artefatos físicos e culturais.

O objeto de estudo selecionado foi a planta da Volkswagen - Caminhões e Ônibus, localizada em Resende - RJ, por ser segundo Pires (2004) "a pioneira e a única na indústria automobilística na utilização integral de um consórcio modular". A planta é resultado de investimentos conjuntos entre a montadora e seus modulistas com o objetivo inicial de produzir 30.000 caminhões e chassis de ônibus por ano. Para a definição dos módulos, a montadora promoveu uma concorrência entre diversos fornecedores tradicionais na indústria automobilística. No total, foram estabelecidos sete modulistas. O relacionamento entre estes fornecedores e a VW baseia-se em um contrato de longo prazo (neste caso cinco anos) podendo ser renegociado.

Foram realizadas entrevistas semi-estruturadas e observação direta como fontes de evidências, visto que foi fundamental a presença do pesquisador no local para se captar as persepções dos atores. O estudo de caso foi conduzido considerando a seguinte questão de pesquisa: Como a estrutura organizacional do consórcio modular auxilia no gerenciamento da cadeia de suprimentos de uma montadora de veículos comerciais? Primeiramente, a questão de pesquisa foi subdividida em quatro áreas principais: integração, coordenação, SCM e Consórcio Modular. A partir dessa subdivisão, originou-se um roteiro de entrevistas que busca maior visualização das informações que precisaram ser coletadas junto aos atores. A Figura 1 apresenta o desdobramento da questão de pesquisa e os principais pontos que foram abordados na condução das entrevistas.

Os atores envolvidos nas entrevistas foram alguns dos gerentes industriais dos módulos pertencentes ao consórcio. Estuda-se, para uma etapa complementar, a extensão das entrevistas a alguns dos principais fornecedores diretos. Um resumo com os resultados parciais do estudo de caso são apresentadas a seguir, conjuntamente com a corroboração de alguns pontos já anteriormente levantados na bibliografia. 


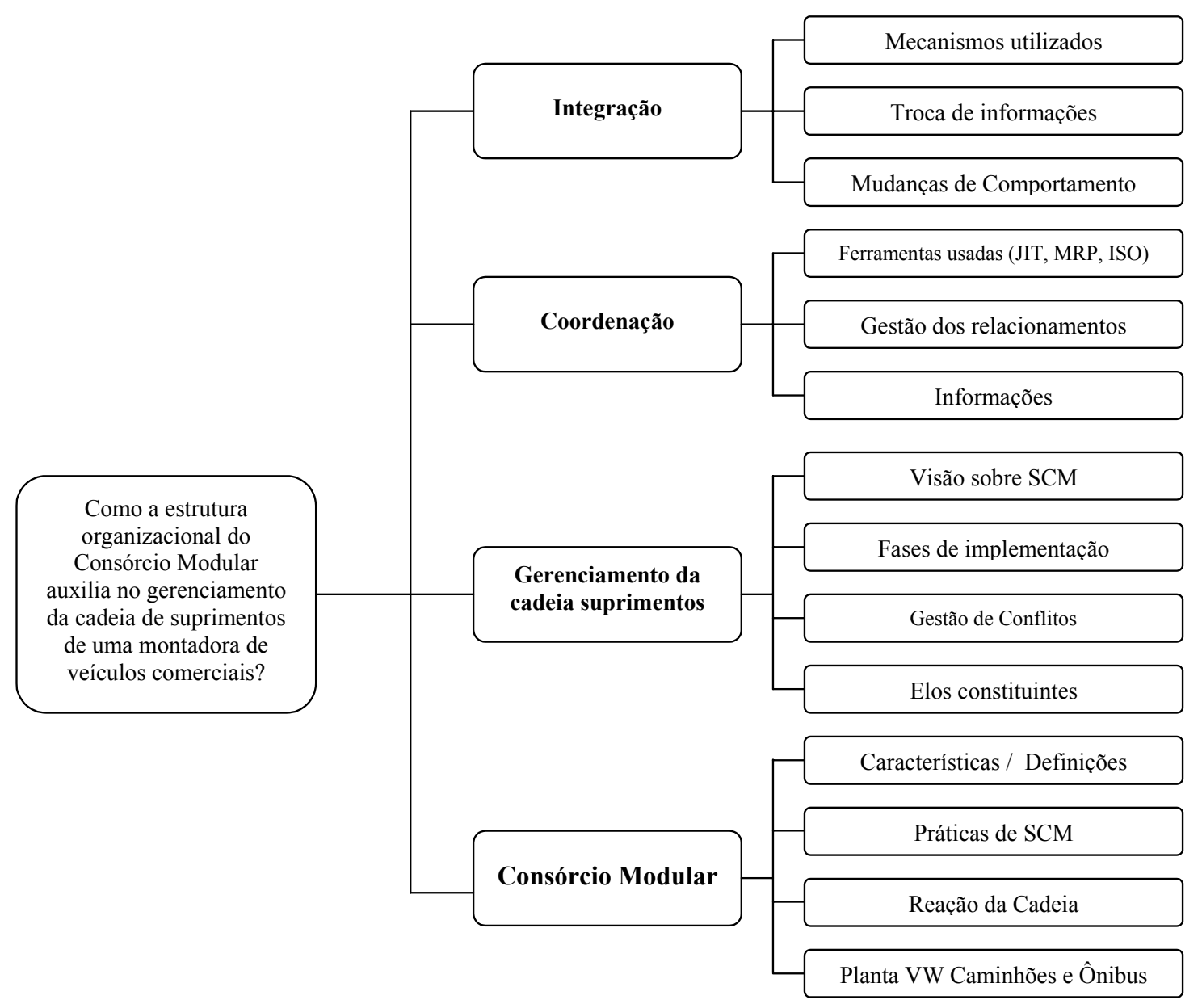

Figura 1- Árvore de desdobramento da questão de pesquisa

\subsection{Observações do estudo de caso}

De uma maneira geral, as práticas citadas na seção 3 são as que de fato apresentam maior destaque no gerenciamento da cadeia de suprimentos da planta. Confirmou-se a observação de Furlaneto (2002), de que a indústria automotiva já opera com suas cadeias integradas, sendo seus fornecedores co-responsabilizados no processo de produção dos veículos, mesmo que estas não estejam estruturadas em consórcios modulares. No entanto, na estrutura do Consórcio Modular nota-se um maior relacionamento com os fornecedores, devido à proximidade física e ao maior envolvimento no projeto e montagem do veículo final.

A adoção do consórcio modular implicou em alguns desafios para os módulos, entre os quais: responsabilidade pelo gerenciamento da cadeia de suprimentos; necessidade de absorção de novas competências; investimentos em infra-estrutura e as operações de montagem. Pires (2004) ressalta alguns dos fatores que podem ser considerados como importantes no sucesso do consórcio modular: a alta capacidade de modularidade dos produtos fabricados e a fácil adaptabilidade da linha de montagem, que de forma flexível permitem a produção de diversos modelos de veículos comerciais. Porém, dificultam o abastecimento da linha devido ao elevado número de peças utilizadas e também o balanceamento da linha, já que o mesmo conjunto pode ser montado por diferentes postos ou até mesmo diferentes módulos dentre os diversos modelos existentes.

No que se refere ao suprimento, a montadora continua responsável pela aquisição das peças que são repassadas aos módulos para que efetuem a montagem. Desta forma, a montadora ainda se relaciona com diversos fornecedores e por motivos de economias de escala, a 
estratégia de manutenção de estoques ainda é utilizada. Outro fator de destaque é a alta necessidade de capital alocado na manutenção dos estoques, o que poderia inviabilizar financeiramente a gestão de alguns módulos.

Não foi mantida a rigidez definida inicialmente quanto ao pagamento dos modulistas. Desta forma, quando ocorre baixo índice de defeitos no pré-teste, o pagamento pode ser adiantado, mesmo que o veículo ainda esteja em fase de aprovação. Os diversos modulistas podem apresentar particulariedades quanto à política de pagamento, definidas em contrato, o que caracteriza certa flexibilidade da montadora no surgimento do consórcio.

O relacionamento com os fornecedores procura se basear na capacidade de comunicação entre as empresas envolvidas e na confiabilidade das informações que circulam na cadeia de suprimentos, mas alguns problemas referentes à confiabilidade nos prazos de entrega das peças foram evidenciados, gerando alguns retrabalhos, que podem ser repassados ao fornecedor dependendo da causa do problema. A seleção dos fornecedores passou a ser realizada através de uma pré-seleção baseada em múltiplos critérios: contratos de longo prazo; foco no custo total do fornecimento; fornecedor único envolvido desde a fase inicial do projeto; avaliação de desempenho criteriosa e investimentos em mecanismos de coordenação. Vale ressaltar ainda que a montadora não desconsidera a importância dos seus subfornecedores: certificações e treinamentos em qualidade estão sendo cada vez mais exigidos dos fornecedores de segundo nível e as negociações comerciais são muitas vezes realizadas diretamente com estes fornecedores.

Destaca-se também importância de se estabelecer indicadores para a avaliação de desempenho da cadeia como um todo. No caso em questão, os indicadores utilizados são os indicadores coorporativos da montadora. Desta forma, algumas considerações quanto à integração entre os elos e a interface entre os diferentes processos acabam sendo desconsideradas.

\section{Considerações Finais}

O objetivo desse trabalho foi analisar as práticas de SCM em uma montadora de veículos comerciais que adota a estrutura de consórcio modular e se responsabiliza pela coordenação da cadeia de suprimentos na qual está inserida. Para tanto, foi realizado um estudo de caso na planta da Volkswagen Caminhões e Ônibus, localizada na cidade de Resende, no qual foram entrevistados alguns dos gerentes industriais dos módulos que compoem o consórcio modular, além de observações diretas efetuadas pelo pesquisador.

Apesar dos resultados serem ainda preliminares, pode-se constatar que o arranjo produtivo tipo Consórcio Modular é mais adequado às atividades relacionadas à montagem do que as de fabricação, além de exigir certo grau de modularidade dos produtos. As vantagens da integração estão relacionadas à agilidade na tomada de decisões relativas à produção e a flexibilidade da linha de montagem, o que acaba permitindo um produto cada vez mais diferenciado. No que se refere ao compartilhamento de informações, o processo vem evoluindo desde a implantação do consórcio modular, já que os módulos participantes do consórcio sofreram algumas adaptações durante esses anos, viabilizando uma convivência mais harmônica entre a montadora e os modulistas.

A montadora continua se responsabilizando pela coordenação da cadeia de suprimentos, desta forma, todas as questões relacionadas à escolha e desenvolvimento dos fornecedores, definição das condições de entrega e as características de contrato permanecem a cargo da montadora. O módulo participa apenas após a aprovação do produto, deste momento em diante ele se responsabiliza por todo fluxo logístico, desde o acionamento dos fornecedores até a alimentação de informações ao operador logístico para o abastecimento da linha de produção. 
Finalmente, cabe ressaltar que, dentro do gerenciamento da cadeia de suprimentos, algumas empresas podem utilizar parcialmente os conceitos do consórcio modular e dos condomínios industriais, considerando a complexidade organizacional da cadeia em que se encontram inseridas e os objetivos do gerenciamento em questão. Sendo assim, a definição das práticas e da intensidade de utilização das mesmas deve ser estabelecida conforme a característica da cadeia de suprimentos a ser gerenciada.

\section{Agradecimentos}

Os autores agradecem à FAPEMIG - Fundação de Amparo à Pesquisa do Estado de Minas Gerais - pelo apoio financeiro concedido ao projeto de pesquisa que deu origem a esse trabalho.

\section{Referências}

BOWERSOX, D. J.; CLOSS, D. J. (2001) - Logística empresarial: o processo de integração da cadeia de suprimento. São Paulo, Atlas.

CABRAL, S. (2004) - Analisando a reconfiguração da cadeia de produção de pneus no Brasil pela economia de custos de transação. Revista Gestão \& Produção. Vol.11, n. 3, p. 373-384.

CARLINI, G. (2002) - A logística integrada como ferramenta para a competitividade em uma agroindústria. Porto Alegre. 127p. Dissertação (Mestrado) - Escola de Administração, Universidade Federal do Rio Grande do Sul.

FLEURY, P. F. (1999) - Supply chain management: conceitos, oportunidades e desafios da implementação. [OnLine] Disponível na Internet via WWW. URL: http://www.cel.coppead.ufrj.br/fs-public.htm Consultado Maio 2005.

FURLANETO, E. L. (2002) - Formação das estruturas de coordenação nas cadeias de suprimentos: estudo de caso em cinco empresas gaúchas. Tese (Doutorado) - Escola de Administração, Universidade Federal do Rio Grande do Sul.

JESUS, G. (2003) - Estudo de caso sobre a medição desempenho da cadeia de suprimentos de uma montadora de autoveículos. Dissertação (Mestrado) - Departamento de Engenharia de Produção, Universidade Federal de São Carlos.

LUMMUS, R. R.; VOKURKA, R. J.(1999) - Defining supply chain management: a historical perspective and practical guidelines. Industrial Management \& Data Systems, Vol. 99, n. 1, p.11-17.

MARX, R.; ZILBOVICIUS, M.; SALERNO, M. S. (1997) - The modular consortium in a new VW truck plant in Brazil: new forms of assembler and supplier relationship. Integrated Manufacturing Systems, Vol. 8, n. 5, p. 292-298.

NÓBREGA JR, J. I.C.(2000) - Metodologia para análise estratégica de projetos de cadeias de abastecimento industriais. Dissertação (Mestrado) - Universidade Federal de Santa Catarina.

PARRA, P. H. (2000) - Análise da gestão da cadeia de suprimentos em uma empresa de computadores. Dissertação (Mestrado) - Faculdade de Engenharia Mecânica e de Produção, Universidade Metodista de Piracicaba.

PIRES, S. R. I. (2004) - Gestão da Cadeia de Suprimentos (Supply Chain Management) - Conceitos, Estratégias e Casos. São Paulo, Atlas.

SIMCHI-LEVI, D.; KAMINSKY, P.; SIMCHI-LEVI, E. (2003) - Cadeia de suprimentos - Projeto e Gestão. Trad. Marcelo Klippel, São Paulo, Bookman.

YIN, R. (2001) - Estudo de caso: planejamento e métodos. Trad. Daniel Grassi. 2a edição, Porto Alegre, Bookman. 